\title{
A message from the ERS President and the ERS Secretary for EU Affairs
}

\author{
Elisabeth Bel ${ }^{1,2}$ and Jean-Paul Sculier ${ }^{3,4}$
}

\begin{abstract}
Affiliations: ${ }^{1}$ ERS President. ${ }^{2}$ Dept of Respiratory Medicine, Academic Medical Center, University of Amsterdam, Amsterdam, The Netherlands. ${ }^{3}$ ERS Secretary for EU Affairs. ${ }^{4}$ Service des Soins Intensifs et Urgences Oncologiques \& Oncologie Thoracique, Institut Jules Bordet, Centre des Tumeurs de l'Université Libre de Bruxelles (CULB), Brussels, Belgium.
\end{abstract}

Correspondence: Jean-Paul Sculier, Service des Soins Intensifs et Urgences Oncologiques \& Oncologie Thoracique, Institut Jules Bordet, Centre des Tumeurs de l'Université Libre de Bruxelles, Brussels, Belgium. E-mail: sculierabordet.be

0 @ERSpublications

The ERS leadership congratulates the European authorities on their support for respiratory research http://ow.ly/RVMew

We would like to emphasise to European Respiratory Society (ERS) members and to all physicians and researchers dealing with respiratory diseases the importance of the editorial written by Adoración Navarro-Torné and distinguished colleagues from the Health Directorate of DG Research and Innovation of the European Commission. The authors rightly note that chronic respiratory diseases (CRDs) (particularly chronic obstructive pulmonary disease (COPD) and asthma) and lung cancer are major causes of morbidity and mortality in the European Union, and have an important economic burden.

We are delighted to see the large number of research projects that the European Union has funded as part of its programmes, such as the Sixth and Seventh Framework Programmes for Research (FP6 and FP7), the Innovative Medicines Initiatives (IMI) 1 and 2, and Horizon 2020. Major research priorities are: furthering the understanding of chronic diseases; the development of personalised medicine, including new biomarkers and drugs; the prevention of infections such as tuberculosis (TB), which have a direct impact on CRDs; and the delivery of patient-centred care. The main respiratory topics involved in the research projects are asthma, COPD, cystic fibrosis, TB, air pollution and lung cancer.

We congratulate the Commission for all its efforts in developing high-quality collaborative research between European institutions and respiratory scientists. We encourage our colleagues to participate to the calls for projects launched by the EU in the context of the current research framework Horizon 2020.

Received: Aug 272015 | Accepted: Aug 282015

Conflict of interest: None declared.

Copyright @ERS 2015 